\title{
Application of TRIZ Technique in the Organizations' Activity
}

\author{
Submitted $21 / 07 / 20,1^{\text {st }}$ revision $12 / 08 / 20,2^{\text {nd }}$ revision $30 / 09 / 20$, accepted $25 / 10 / 20$

\section{Sklyarova O.A. ${ }^{1}$, Musaelyan A.K. ${ }^{2}$, Bukhov N.V. ${ }^{3}$ Medvedeva L.S. ${ }^{4}$, Bidzhieva A.S. ${ }^{5}$}

\begin{abstract}
:
Purpose: The article is aimed at identifying and evaluating the capabilities and main components of the theory of inventive problem solving, expanding its effective application, in terms of describing its methods, tools and the development prospects using TRIZ.

Design/Methodology/Approach: For the TRIZ development it is necessary to identify the place of the TRIZ in the search for solutions in the functional and cost analysis, to identify the principles and formulate goals for which the TRIZ can be used, to determine the basic provisions of the theory of solving inventive problems and levels of problems in the TRIZ, to show the process of the TRIZ practical application in carrying out the functional and cost analysis of the enterprise organizational structure.

Findings: The functional analysis, as one of the TRIZ key tools, is aimed at identifying functions, their characteristics in the context of the system (technological, managerial, business system). This direction is used to reveal system shortcomings such as harmful functions, insufficiently useful functions, the excessive components cost, and also nonperformance of required functions by the analyzed object, and also it is to prepare the system model which will be applied at the subsequent stages of the analysis.

Practical Implications: The results of the study could be implemented in the practice of various organizations for technical, technological, managerial, and business systems.

Originality/Value: The main contribution of this study is to shift the TRIZ focus to various non-technical type of activities and to improve its application efficiency using its methodology and tools.
\end{abstract}

Keywords: TRIZ, ARIZ, FCA, search for solutions, business system.

JEL code: $O 22$.

Paper Type: Research paper.

\footnotetext{
${ }^{l}$ PhD (in Economics), Associate Professor of the Analysis of Economic Activity and Forecasting Department, Rostov State University of Economics, Rostov-on-Don, Russian Federation,ahd73@bk.ru;

${ }^{2}$ PhD in Economics, Associate Professor, Rostov-on-Don, Russian Federation.

${ }^{3}$ Senior lecturer of the Accounting Department, Rostov State University of Economics, Rostov-on-Don, Russian Federation, bnvscience@gmail.com;

${ }^{4} \mathrm{PhD}$ (in Economics), Associate Professor of the Economics and Management Department, Don State Technical University, Rostov-on-Don, Russian Federation, milla1988@mail.ru; ${ }^{5}$ Post graduate of the Analysis of Economic Activity and Forecasting Department, Rostov State University of Economics, Rostov-on-Don, Russian Federation, a.s.bidjieva@mail.ru;
} 


\section{Introduction}

The modern business environment is characterized by its dynamism. Information techniques and global trends used to allow businesses to stay in a comfortable environment are removing boundaries. The market is constantly demanding better services, bringing the competition even between small businesses to the global level. In a search for solutions more and more organizations are turning their attention to the TRIZ (theory of solving inventive problems) and the FCA (functional and cost analysis) / VA (value analysis).

The characteristic feature of the functional and cost analysis is the search for new solutions in the object analysis. There are two key types of the search for solutions, often combined in the functional and cost analysis (information and heuristic one) (Figure 1). The informational search is the search for the specific problem solution among solutions known from the informational sources. The heuristic search is a creative search for original, non-standard solutions with invention elements. The FCA uses creative methods ${ }^{6}$ to generate new ideas and proposals. The most famous ones are: the brainstorming method, synectic method, morphological method, method "Delphi", pattern method, method of control questions, method of focal objects, TRIZ (Sklyarova, 2011).

\section{Materials and Methods}

TRIZ was developed as a theory and a set of applied tools to support the solution of so-called "extraordinary" problems in technics and engineering: problems that cannot be solved by known formal methods, such as the mathematical optimization or configuration change. They require new, non-standard solutions, unknown before. To develop the TRIZ, the Russian inventor Heinrich Altschuller (the TRIZ founder) and his colleagues studied a lot of technological solutions, patents, inventions and extracted a number of common models of the solution (Altschuller, 1994; 1999).

One more important achievement of the TRIZ research was the discovery of mechanisms that helped to transform the original problem situation by solving the inventive problem at an abstract level, thus greatly reducing the space to find a solution by directly navigating in the area of the most relevant solution (Figure 2). This approach helps to reuse the previous experience available as a set of the highorder solution templates and reduces the time and effort required to solve innovative problems. In fact, Heinrich Altschuller was the first to apply an empirical scientific approach to the solution of problems that require creative thinking and cannot be processed by formal methods. Over the years, he studied hundreds of thousands of solutions and concluded that the proposed solutions correspond to a relatively small set of abstract solution patterns. A breakthrough solution arises because of the contradiction elimination that is a serious barrier that prevents to solve the problem.

\footnotetext{
${ }^{6}$ Method is a systematized set of steps, actions aimed at solving a certain task or achieving a certain goal.
} 
Figure 1. Types of the search for solutions in VA(Sklyarova, 2017)

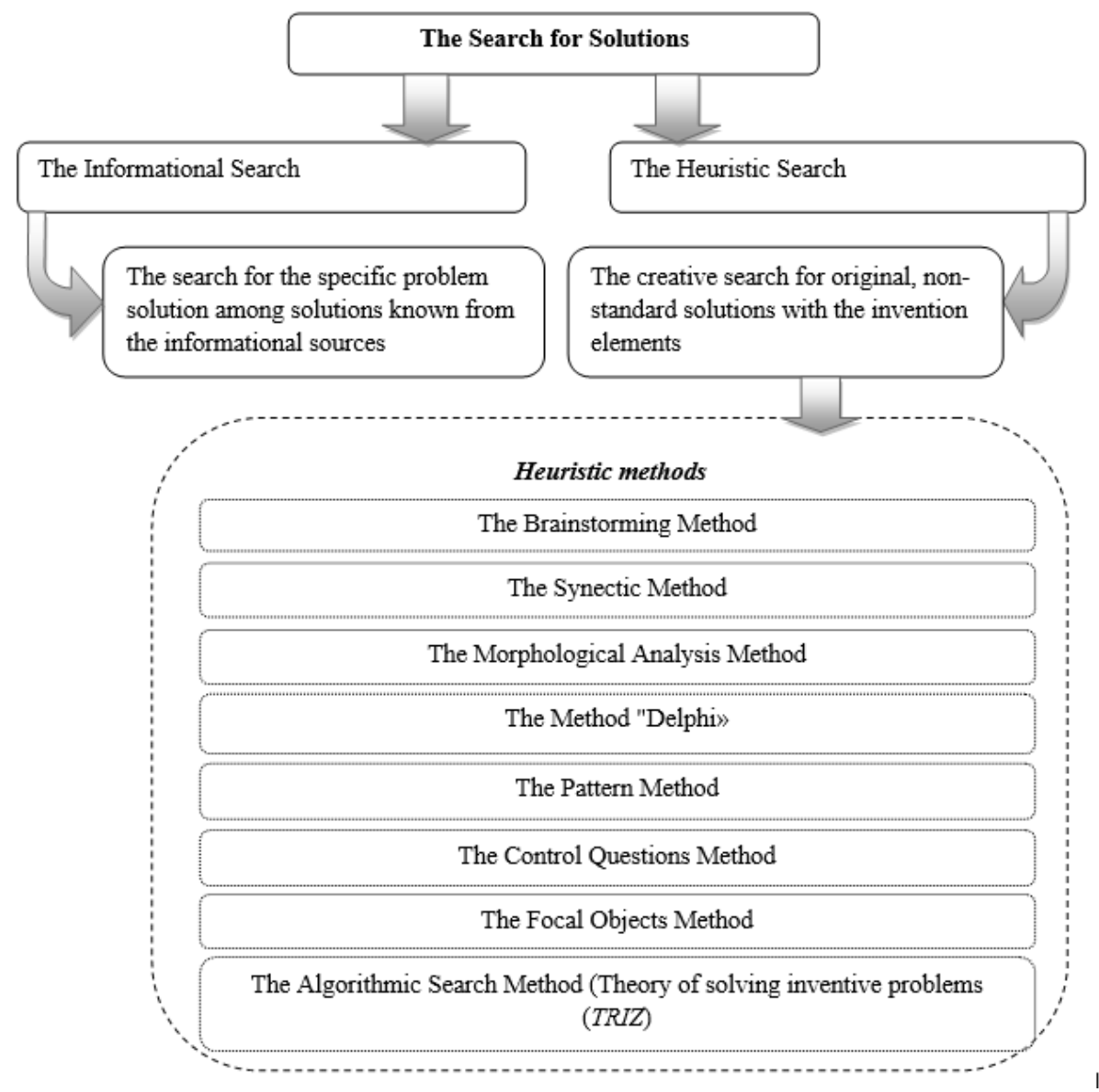

Breakthrough solutions, sometimes called as "revolutionary" innovations, do not come unexpectedly. They appear as a symmetrical response to the need to move beyond the constraints imposed by legacy solutions. Breakthrough solutions requires the breakthrough thinking. The breakthrough thinking forces to think outside the box, we must distract from the concepts associated with a specific problem being solved at the moment, forget about existing solutions, consider the problem in a different ways of looking. Over the years of evolution, the TRIZ researchers introduced a number of different methods and tools that support different stages of the innovative problem and innovative plans solution.

In recent years, a number of the TRIZ researchers and practitioners have been experimenting with extending the TRIZ to a number of non-technical areas, including business and management systems. The main prerequisite of such experiments is that the TRIZ methods for solving complex problems that require creative thinking is independent on the application and can analyze all the problems that arise in nontechnical systems, such as technological, social, cultural, artistic ones and so on. The 
TRIZ blends into a common method that can be effectively applied in many areas to solve problems, including solving business and management conflicts.

In general, regardless of the application area, today the TRIZ methods and tools can be used in the following situations:

$>$ Solving a specific problem that is formulated as a negative or undesirable effect or as a lack of necessary performance or control (low, insufficient sales, poor supply chain management).

$>$ Investigating the system (business or technological one), identifying bottlenecks and barriers that can be eliminated with innovative solutions made with the use of the TRIZ tools and its methods.

$>$ Analyzing the evolutionary potential of a technological or business system and proposing strategies for the development of the next system generations.

$>$ Predicting possible failures in the new products and processes and help with their prevention.

Figure 2. Task levels in the TRIZ (Kovalev et al., 1988)

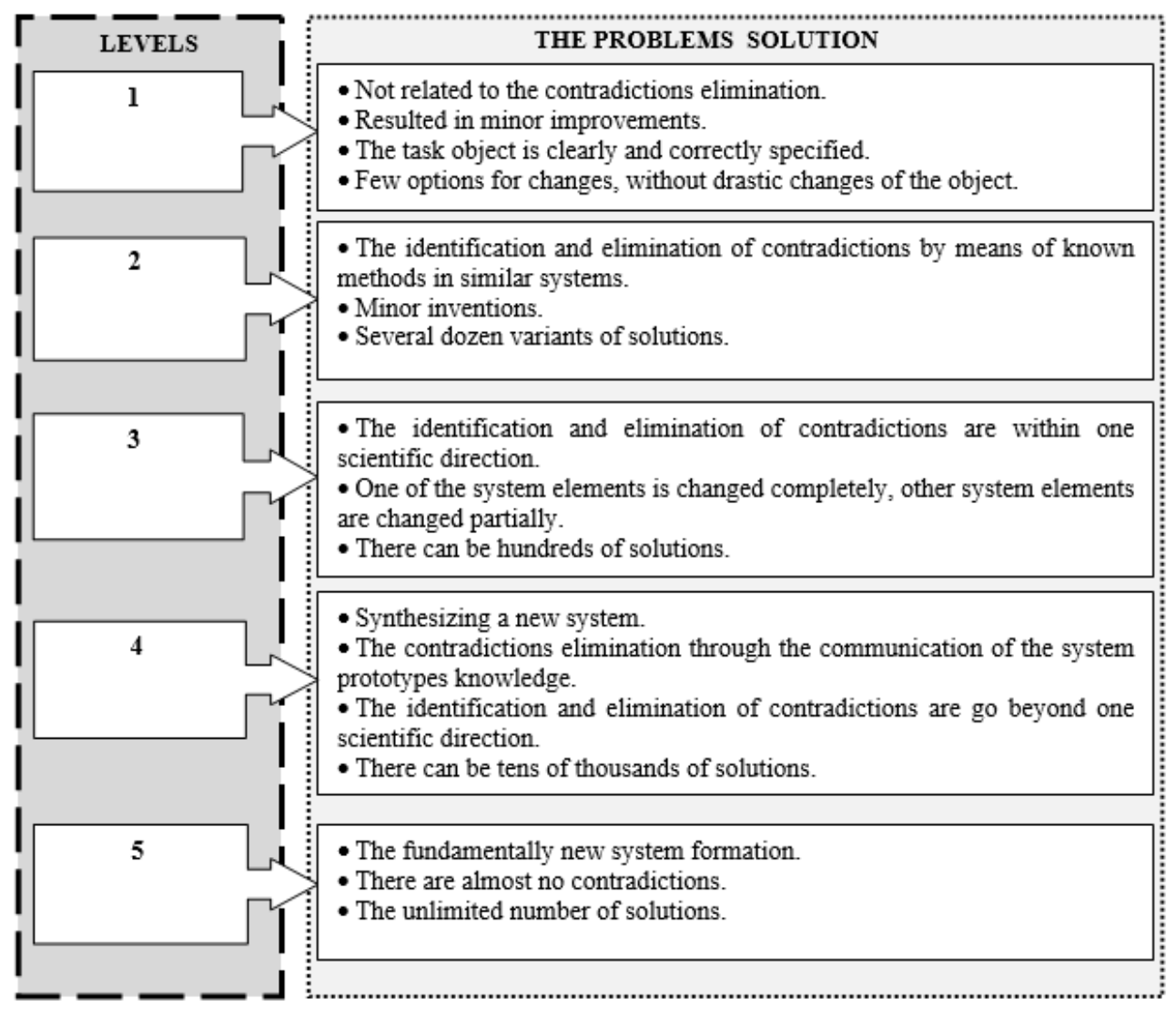


The modern TRIZ is a rather large number of knowledge, which is a combination of the evolving theory of the inventive problem solving, analytical tools, methods and techniques for solving problems, a lot of data on specific practical opportunities and methods for the creative search development.

Although most of the TRIZ main principles were taken from the technical inventions research, the ways in which problems are solved at the present stage and ideas are generated are quite similar in almost all the areas (social, political, business, economic one). According to the TRIZ postulate one of the main driving forces of the certain technology evolution is the gradual resolution of emerging contradictions between current technological capabilities and growing requirements.

One of the most TRIZ significant contributions was that it defined strategies and models for solving contradictions: both solving contradictions in time and space, and in more specific cases, for example, considering the possibility to perform the opposite action instead of the intended one. The high degree of abstraction makes the main TRIZ discoveries and principles independent on creative problem solving. Today the TRIZ is used in business, architecture software, marketing, advertising, Pedagogics. The TRIZ is gradually moving towards a universal problem-solving paradigm based on a heuristic approach for generating breakthrough ideas.

After identifying the contradiction, it is necessary to find the solutions either not to eliminate it, or to eliminate it using a number of tools, depending on the contradiction complexity. The most popular technique for the most of problems is the so-called "contradiction Matrix", which provides the systematic access to the most relevant subset of inventive principles depending on the contradiction type. Although the inventive principles look the same both for the technics and business and management, but matrices are different. While the matrix for technical systems was originally developed by G. Altschuller in the 1960s, later Darrell Mann created the matrix of contradictions for the TRIZ in business and management. (Mann and Domb, 1999; Mann, 2004).

If the contradiction cannot be solved with a matrix, there are more complex methods such as the ARIZ (Algorithm for solving inventive problems). The TRIZ principle is a target search for the inventive problem solution by the algorithm for solving inventive problems (ARIZ). The ARIZ is one of the methods recommended in several publications on the FCA (VA), and focuses on the ideal result, while identifying and eliminating contradictions. The ARIZ main provisions are (Usenko et al., 2008):

$>$ Top-level tasks are reduced to the lowest level, for which through special operators the physical contradiction is identified in the object.

$>$ To overcome physical contradictions, the inventive techniques fund is created. It is formed in a form of tables of the techniques use depending on the task type or the contradiction contained in it. 
$>$ Tables of the effects' application which with the inventive receptions fund form the ARIZ information fund.

$>$ At each step of the ARIZ all the possible techniques to activate the imagination and overcome the psychological inertia of thinking should be used.

\section{Results}

In many situations, defining and resolving only one contradiction may not be enough. Complex problems and complex tasks are usually characterized by many interrelated contradictions. In some cases, the resolution of one contradiction will not be necessarily resulted in the expected solution. Changing one part of the system usually leads to changes in other parts. Therefore, to move in the right direction, it is necessary to identify and solve the problem within the system to identify the full picture. The more precisely we define all the components of a common problem, the easier it will be to understand the origins of contradictions and find exactly at what level the problem should be solved.

One of the TRIZ tools is known as the function analysis. This technique helps to identify negative, insufficient, or poorly managed interactions within a system and to find "weaknesses" in different types of systems. Methods can be applied in technology, logistics, business services, etc. It is important that the functional interaction analysis helps to identify "hidden" unwanted interactions that either reduce the system efficiency or may be the potential failures source, thus revealing the ability for the further improvement. In addition, the TRIZ-based function analysis helps rank functions provided by the systems and create a functional hierarchy that establishes different cost levels for the system elements functions. The TRIZ-based function analysis is also used to create easier and more ideal business systems. The function analysis, according to the modern TRIZ, is an analytical tool determining functions, their characteristics, and the cost of system and suprasystem components (Gerasimov and Litvin, 1991). The analysis is necessary for identifying the system disadvantages such as harmful functions, underperforming or overperforming useful functions, excessive component costs, incorrect location and time of functions, or lack of functions. Another purpose of the function analysis is to prepare a system model for the use in the subsequent analysis steps.

The overall complexity of the problem is caused by a number of contradictions that contribute to some extent to the overall negative effect. A contradiction can resolve another contradiction. The best scenario is to find a single solution to eliminate all the alternative causes at the same time. The next step is to choose the contradiction for the analyze and solution with the greatest impact on the main negative effect. The relationships in the whole chain of causes that contribute to the negative effect must be eliminated. Solving a single contradiction can't always eliminate a negative effect, because several independent contradictions can create a negative result in different parts of the system. 
Depending on the solution objectives, that is, the consequences and scope of the solution, there are three strategies for choosing the contradiction:

$>$ Choosing the greatest contradiction in the chain that contributes to the underlying negative trend.

$>$ Choosing the root contradiction.

$>$ The integration of the two previous approaches and the comparative ranking of all the contradictions along the entire selected chain of contradictions.

In Rostov State University of Economics, the TRIZ technique has been effectively used for several years. Students complete specific practical tasks in the discipline "The functional and cost analysis" like considering the specific situation at the working enterprise of Rostov-on-Don, students are invited to:

$>$ in accordance with the company organizational structure to make a matrix of the actual company functions and distribute into each of the structure links the functions performed by them. These functions should be divided into the main functions, auxiliary functions and unnecessary ones, determining their cost in a expert way;

$>$ define the goals and objectives of the company;

$>$ to transform (or leave unchanged) the organizational structure in accordance with the goals, objectives of the company and in accordance with the analytical work organization in it;

$>$ define functions for each link of the newly created organizational company structure with the preparation of the potential functions matrix;

$>$ prepare the project presentation in a small analytical group.

At the stage of the discussion in small groups, students distribute among each other various functional roles (leader, speaker, secretary, generator of ideas, critic, etc.) and within definite time, try to develop their own answer the questions, working out the sequence of steps to make a decision:

$>$ the situation analysis;

$>$ the problem identification;

$>$ the search for the factors characterizing it;

$>$ the development of alternatives to its solution;

$>$ the selection and substantiation;

$>$ the preparation for the group's solution presentation.

In every small group (regardless of other groups) individual problem solutions are compared, their completion, the development of the uniform common position which is made out in writing. At the end of the work in small groups, students should formulate their (collective) version of the problem solution and present it for discussion. At the stage of presenting the group decisions and their plenary discussion, the group speakers present the group decision in a predetermined form and answer 
clarifying questions of the audience and the lecture. The presentations contain the situation analysis using the appropriate methods from the theoretical course; both the content of the solution and the presentation technique are evaluated.

Group training using the TRIZ methods is characterized by an open concept: goals are realized and appropriate solutions are developed basing on the training tasks or problems. Then they are presented to the open discussion by all the participants.

Group projects organize students in small groups to perform a certain task (as usual the solution of a certain problem) with its subsequent formulation and presentation of the results for the analysis. Almost all the active teaching methods use some elements of group tasks, but group projects are characterized by the formal moment. It is a clearly defined the group structure, timing and form of presenting results.

\section{Conclusion}

Thus, the TRIZ for managerial, business purposes prove its efficiency in practice now. The TRIZ and FCA are increasingly used in the development of management and business solutions, such as: improving sales efficiency; creating a new marketing conception that helps to increase sales; resolving a number of contradictions in the supply chain; developing a new business model; improving the efficiency of trainings; improving the degree of service perfection: increasing the value while reducing costs; predicting potential failures of a new business model, etc. It is necessary to continue studying trends and models of the business systems development and effectively use the theory of inventive problem solving them. The advantage of the TRIZ technique is that it can be used to identify a wide range of problems and challenges, and can be used with other analytical tools.

\section{References:}

Altschuller, G, 1999. The Innovation Algorithm. TRIZ, Systematic Innovation, and Technical Creativity. Technical Innovation Center, Inc., Worcester.

Altschuller, G. 1994. Creativity as an Exact Science. Gordon and Breach Publishers.

Gerasimov, V.M., Litvin, S.S. 1991. Basic statements of methodology for performing function-cost analysis: Methodological recommendations. Moscow, Russia, «InformFCA».

Kovalev, A.P., Moiseeva, N.K., Sysun, V.V. 1988. Handbook of Functional and Cost Analysis. Moscow, Finance and Statistics, 431.

Mann, D., 2004. Hands-on Systematic Innovation for Business and Management. Lazarus Press.

Mann, D., Domb, E. 1999. 40 Inventive (Management) Principles with Examples. The TRIZ Journal, September, available online: http://www.trizjournal.com/archives/1999/09/a/index.htm.

Sklyarova, O.A. 2011. Methods for the Creative Search Activation in the Functional and Cost Analysis. Actual problems of Accounting, Analysis, Audit, Statistics and 
Taxation: VI All-Russian Scientific and Practical Conference. Rostov-on-Don, RSUE, 219.

Sklyarova, O.A. 2017. Functional and Cost Analysis. Rostov-on-Don, RSUE, 107.

Usenko, L.N., Bogataya, I.N., Bukhov, N.V., Kuvaldina, T.B., Pavlyuk, A.V. 2018.

Formation of an integrated accounting and analytical management system for value analysis purposes. European Research Studies Journal, 21(S1), 63-71.

Usenko, L.N., Sklyarova, O.A., Sheravner, V.M. 2008. The Functional and Cost Analysis in the Commercial Organizations: theory and practice. Rostov-on-Don, SFEDU Publ., 223. 